\title{
A DINÂMICA ECONÔMICA RECENTE DO ESTADO DE MATO GROSSO DO SUL: UMA ANÁLISE DA COMPOSIÇÃO REGIONAL E SETORIAL
}

\section{THE ECONOMIC DYNAMICS OF MATO GROSSO DO SUL: AN ANALYSIS OF REGIONAL AND SECTORAL COMPOSITION}

\author{
Fabricio Jose Missio \\ Universidade Estadual de Mato Grosso do Sul - MS - Brasil \\ Rosele Marques Vieira \\ Universidade Estadual de Mato Grosso do Sul - MS - Brasil
}

\begin{abstract}
Resumo: O artigo analisa a dinâmica econômica recente do estado de Mato Grosso do Sul (20022009), com o objetivo de mostrar as transformações setoriais e intrarregionais que acompanham o crescimento econômico do estado. Mais especificamente, o objetivo é mostrar como a evolução recente das estruturas, em termos de setores e de regiões, acompanham as mudanças no processo de desenvolvimento do MS, em especial, a partir das transformações do campo e das políticas de incentivos. As considerações finais mostram que apesar das mudanças recentes na produção, permanecem no estado elementos que marcam a sua formação histórico-econômica, como aquele relacionado às políticas de desenvolvimento regional que determinam forte orientação agrícola.

Palavras-chave: Desenvolvimento regional, composição setorial e produção agrícola.
\end{abstract}

Abstract: The article analyzes the dynamics economic of the state of Mato Grosso do Sul (20022009), with the aim of showing the changes accompanying sectoral and intra-regional economic growth of the state. More specifically, the aim is to show how the recent evolution of structures in terms of sectors and regions, follow the changes in the development of MS, especially from the transformations of the field and policy incentives. The final considerations show that despite recent changes in production, remain in state elements which mark its historical-economic formation, such as those related to regional development policies that determine strong agricultural orientation.

Key words: Regional development, sector composition and agricultural production.

\section{Introdução}

As mudanças na economia brasileira a partir da década de 1990, associadas principalmente ao processo de abertura comercial, produtiva e financeira e à política de "estado mínimo", não foram capazes de garantir o dinamismo da economia nas últimas duas décadas. Com isso, as elevadas disparidades regionais observadas se mantiveram, evidenciando a necessidade de serem definidas novas políticas para o desenvolvimento das regiões mais atrasadas.

Apesar de estudos sugerirem a presença de uma pequena força no sentido da desconcentração regional, as mudanças foram pouco significativas ao longo das últimas duas décadas. Ademais, grande parte das mudanças locais de produção está muito mais associada aos incentivos fiscais e creditícios oferecidos pelos governos locais, do que a um movimento propriamente dito de desconcentração da produção.

No que se refere ao estado de Mato Grosso do Sul, a contextualização histórica permite evidenciar que as políticas direcionadas ao desenvolvimento da 
fronteira agrícola e outros programas de incentivo para a região Centro-Oeste beneficiaram o desenvolvimento do estado. Atualmente, destaca-se a evolução e a modernização agrícola que culminaram em ganhos de produção e de produtividade, bem como a implantação das agroindústrias e, mais recentemente, a expansão do setor sucroalcooleiro. Nesse contexto, o objetivo deste artigo é mostrar as transformações setoriais e intrarregionais que acompanham o crescimento econômico recente do estado de Mato Grosso do Sul (MS). Para tanto, do ponto de vista metodológico, analisamos a evolução, a participação e a composição setorial e das microrregiões no PIB do MS.

Para cumprir com o objetivo, este artigo encontra-se dividido em cinco seções, além desta introdução e das considerações finais. A seção 2 faz um breve resgate da contextualização história e política da formação do MS; em seguida, é analisada a dinâmica setorial através das suas respectivas participação, composição e taxas de crescimento. Na seção 4 realiza-se uma análise regional a partir da composição setorial microrregional; e na 5 ressaltam-se as transformações recentes no subsetor da produção de grãos a partir da evolução das principais culturas agrícolas.

\section{Breve Contextualização Histórica e Política da Formação do MS}

Ressalta-se que foi no ano de 1977, por meio da Lei complementar $n^{\circ} 31$, que se criou o Estado de Mato Grosso do Sul, pelo desmembramento de uma parte da área do então Estado de Mato Grosso (MT). Nesse sentido, a contextualização histórico-econômica do MS está associada (em certos períodos é difícil fazer a dissociação) com a do MT e, mais especificamente, com a da região centro-oeste como um todo. Isso implica que muitas das políticas desenvolvidas foram concebidas levando-se em consideração a região na qual o Estado encontrase geograficamente inserido; sobretudo, porque grande parte dessa região caracteriza-se por questões limitrófes.

O processo de formação econômica, política e social do MS começa com as primeiras excursões dos colonizadores portugueses e espanhóis, motivados pela busca em extrair produtos capazes de serem comercializados com a metrópole. Não havia, portanto, quase nenhum interesse por parte desses em ocupar a região, de tal forma que até o inicio do século XVIII essa extensa área permaneceu inerte no que se refere ao movimento de ocupação e, consequentemente, de expansão demográfica e do próprio processo de acumulação de capital. O primeiro ímpeto de ocupação da região ocorre quando da descoberta das minas de ouro em Cuiabá, em 1718. A partir desse período, começam a ser construídos fortes e vilas nessa região, dando inicio à efetiva colonização e ocupação das terras situadas ao norte da província de Mato Grosso. Não obstante, o ciclo do ouro entra em decadência e inicia-se um processo inverso com gradativo esvaziado da região (GARCIA, 2001; ESSELIN, 2009; QUEIROZ, 2009).

Do ponto de vista da sua formação, esse é um fato importante para o MS pois o ciclo da mineração fez com que os portugueses perdessem o interesse com essa parte meridional da província. Em contrapartida, essa região passou a receber 
a presença de espanhóis, o que despertou posteriormente a preocupação dos portugueses. A partir de então, os mesmos procuraram firmar a posse de pontos estratégicos no extremo sul da província, tendo em vista um possível litígio fronteiriço.

O segundo grande movimento, quando começa o processo de ocupação efetiva do território do atual estado de Mato Grosso do Sul, tem início apenas nas primeiras décadas do século XIX. Dois são os fatores de destaque: i) o movimento de migração originário do Rio Grande do Sul após 1840; e, ii) a proibição, em 1854, por parte do ditador paraguaio Carlos Lopez, da navegação no rio Paraguai. Neste caso, o Império brasileiro passou a implantar estratégias mais efetivas de militarização do território, ampliando as defesas e construindo as primeiras colônias militares junto às principais rotas de circulação e dos limites fronteiriços.

Ao longo de todo esse período a economia da região (província de Mato Grosso) vivenciou um processo de aprofundamento da estagnação econômica. Em grande parte, a mesma dependia quase que exclusivamente de recursos do governo central, possuindo um aparelho estatal bastante incipiente, uma organização política frágil e uma sociedade que "continha elementos de dispersão evidentes" (GARCIA, 2001, p.15). Ademais, a situação se agrava com a invasão do território do sul da província e a posterior Guerra do Paraguai. A guerra interrompeu o incipiente processo de desenvolvimento e, além da destruição das principais vilas que existiam no período (sobretudo Corumbá e Miranda), interrompeu também a ligação fluvial com o litoral e a Corte. Isso implicou a suspensão do fornecimento de produtos essenciais, com a consequente elevação do nível de preços e o agravamento da fome. Em síntese, a guerra gerou um processo de estagnação econômica no norte da província e deixou o sul devastado, com vilas destruídas, economias desarticuladas e um grande vazio populacional (CORRÊA, 2006).

Um terceiro momento pode ser identificado a partir do fim do referido conflito. Este acabou por promover mudanças significativas no processo histórico e, sobretudo, econômico da região, a qual passou a ser influenciada pela região do Rio da Prata. Ademais, o governo imperial adotou medidas que estimularam a economia local, principalmente a região sul do Pantanal. A primeira delas foi a obtenção da livre navegação pelo rio Paraguai e seus afluentes. Segundo Corrêa (2006), com impulso econômico, Corumbá (cidade portuária) passou a ser a porta de entrada para a província de Mato Grosso, tornando-se o mais importante entreposto comercial da província. Do ponto de vista econômico isso significou contatos mais assíduos com praças comerciais e financeiras estrangeiras, bem como a chegada de embarcações de todas as partes do mundo e a entrada de investimentos estrangeiros tanto no setor agropecuário como no comércio de importação e exportação.

Nesse contexto, fato especialmente importante para a formação do MS foi o inicio do processo de extração da erva-mate, cujo desenvolvimento se transformou num marco histórico na socioeconomia sul-matogrossense. A extração da ervamate se desenvolveu no extremo sul da província, na fronteira com o Paraguai e sua exploração econômica se inicia após a finalização dos trabalhos da comissão de 
demarcação da fronteira em novembro de 1874. Surge a empresa denominada Companhia Mate Laranjeira, que chegou a auferir renda maior que a do Estado.

O desenvolvimento do setor ervateiro atraiu colonizadores oriundos, principalmente, do estado do Rio Grande do Sul. Com o propósito de explorar os ervais, esses colonizadores geraram conflitos entre os interesses do Estado na colonização da fronteira e os interesses da Empresa Mate, que procurava impedir a vinda dos colonos do sul do país. Esses conflitos, presentes também na esfera federal, fomentaram a partir do início do século XX uma política de ocupação da região Centro-Oeste e, principalmente, das regiões de fronteira, voltada para a integração dessas regiões ao conjunto da economia nacional, enfraquecendo suas ligações com os mercados da bacia do prata. Nesse período, a região sul recebeu a ligação ferroviária entre o interior paulista e as margens do rio Paraguai, com a implantação da estrada de ferro Noroeste do Brasil. Essa ferrovia permitiu ao sul uma ligação direta com São Paulo e Rio de Janeiro e deslocou o eixo econômico do estado de Corumbá para Campo Grande, mantendo Cuiaba à margem do processo de desenvolvimento.

A implantação da estrada de ferro Noroeste representava uma estratégia de segurança nacional devido à fragilidade da ligação da região com o centro econômico do país. A marcha para o oeste ganha novos contorno durante o governo de Vargas, de 1930 a 1945, quando foram lançadas as bases da industrialização nacional e o Estado passa a atuar como indutor do processo de desenvolvimento econômico. A estratégia do governo era centralizar o poder político, assumindo maior responsabilidade pelo desenvolvimento econômico do país e pelo bem-estar social, reforçando o controle sobres as elites regionais. A 'marcha para o oeste' significava a solução dos desequilíbrios na distribuição demográfica e no desenvolvimento econômico do país (facilitada pela ferrovia) (ABREU, 2001; FARIA, 1998).

Do ponto de vista das políticas de desenvolvimento implementadas pelo governo federal, destaca-se que, de uma maneira geral, nas décadas de 1970 e 1980 foram intensificados os investimentos a fim de desenvolver as regiões menos desenvolvidas e, com isso, muitas dessas políticas passaram a incorporar o MS. Juntamente com o I e II PND (Plano Nacional de Desenvolvimento), criou-se a Superintendência de Desenvolvimento de Centro Oeste (Sudeco). Essa superintendência foi criada para promover o desenvolvimento da região ou, mais especificamente, para promover a expansão da fronteira agrícola. Predominando "a ideia de 'espaço a ser ocupado' pelo capital a ser atraído". As áreas programas, consideradas 'vazios', recebiam incentivos e investimentos promovidos pelas políticas de desenvolvimento regional. Durante o período da ditadura militar assume importância estratégica o desenvolvimento da agricultura comercial moderna voltada para a exportação.

A região também obteve uma série de incentivos que proporcionaram, entre outras, a melhoria na infraestrutura através de programas específicos, assim identificados (Abreu, 2001; Pavão, 2005):

a) Programa de Desenvolvimento da Grande Dourados (Prodegran) - lançado em Abril de 1976 com o objetivo de modernizar a agricultura e a pecuária na região 
de Dourados (abrangia vinte e dois municípios) ${ }^{1}$. Na justificativa da Sudeco, essa era uma área com elevada produtividade que se encontrava sob influência direta do estado de São Paulo. Vislumbrava-se, pois, a ampliação da agropecuária, objetivando a exportação em consonância com os objetivos do II PND.

b) Programa de Desenvolvimento do Pantanal (Prodepan) - desenvolvido pela Sudeco no período de 1974 a 1978 com o objetivo de expandir estradas, pontes, armazéns e frigoríficos, entre outros.

c) Programa de Desenvolvimento do Cerrado (Polocentro) - criado em 1975, abrangia inicialmente quatro áreas selecionadas: Campo Grande/Três Lagoas; Bodoquena; e Xavantina e Parecis. No último trimestre de 1979, foi criada também a área de Cuiabá-Rondonópolis. O objetivo era desenvolver áreas desocupadas através da modernização agropecuária e das atividades florestais. Não obstante, na agricultura, incentivava-se o cultivo da soja.

d) Programa Nacional do Álcool (Proálcool) - criado em 1975, foi o último programa na década de 1970 e tinha como objetivo principal a substituição do petróleo importado. O governo subsidiou a instalação das destilarias para a produção do álcool etílico nas regiões Norte e Leste de Mato Grosso do Sul.

Enfim, grande parte do desenvolvimento do MS faz parte de uma estratégia espacial desenvolvida por uma política regional que passava a incorporar os conceitos de desconcentração do desenvolvimento e de especialização. Nesse contexto, as políticas de expansão da fronteira agrícola inseriu a região sulmatogrossense no cenário internacional como fornecedora de commodities, gerando ganhos econômicos e divisas para o país. Essa especialização refletia tanto os interesses nacionais como os internacionais quanto ao papel do Brasil e do oeste brasileiro na conjuntura mundial. Observa-se, ainda, que dada sua localização, o sul do até então estado do Mato Grosso possuía vantagens sobre o Norte devido a suas fronteiras com outros países e com a região sudeste, integrando-se, assim, aos corredores de exportação de São Paulo e Paraná, o que influenciava estrategicamente no escoamento da produção. O estado se consolidou como fronteira agrícola a partir da produção de matérias-primas e alimentos para exportação.

Dessa forma, é possível observar que nesse período o MS apresentou um crescimento substancial influenciado pelas políticas de modernização agrícola e pelos investimentos em infraestrutura realizados pelos governos estaduais e federais, ocasionando a expansão do setor primário. Em outros termos, as principais políticas de desenvolvimento são responsáveis em grande parte pela inserção econômica do estado no âmbito nacional. Enquanto a economia brasileira, em meados dos anos 1980, passava por um ajuste recessivo e pela desaceleração de investimentos, o estado iniciava a fase de modernização da agropecuária

\footnotetext{
1 Sendo eles: Amambaí, Anaurilândia, Antonio João, Bataguassu, Bataiporã, Bela Vista, Caarapó, Dourados, Fátima do Sul, Gloria de Dourados, Guia Lopes da Laguna, Iguatemi, Itaporã, Ivinhema, Jardim, Jateí, Maracaju, Navirai, Nova Andradina, Ponta Porã, Rio Brilhante e Sidrolândia.
} 
comercial. Ademais, a evolução urbana demográfica do estado de Mato Grosso do Sul ocorreu acompanhando a conformação da economia do Sul de Mato Grosso.

Segundo Reis Neto (2000), nesse período é possível constatar ainda que a região do atual estado do MS experimenta importantes transformações com o aumento da área plantada de soja, trigo, pastagens e no melhoramento e aumento do rebanho de corte. Ainda segundo o autor, o estado teve no desenvolvimento da agropecuária, em conjunto com a nova indústria sucroalcooleira, oportunidade para o crescimento e o desenvolvimento da agroindústria.

Em síntese, o processo de modernização da agricultura implementado na região teve início durante os governos militares (1964-1985). Contudo, se por um lado se admite que esses programas tenham aportado desenvolvimento e expansão para a produção agropecuária no MS, por outro, é possível identificar que tais programas não foram capazes de fornecer crédito aos pequenos proprietários, determinando um caráter seletivo dessas políticas que beneficiaram, em especial, os grandes proprietários de terras. Evidentemente, essas políticas têm forte influência até hoje, sobretudo, no que se refere à distribuição de renda e à concentração da propriedade (latifúndios).

\section{Aspectos Econômicos}

Ao comparar a taxa real de crescimento do PIB do MS em relação ao PIB nacional, é possível observar que o primeiro cresceu a uma taxa superior ao segundo no período de 2002 a 2009, com exceção do ano de 2004 (Figura 1). No ano de 2003, a taxa de crescimento do PIB/MS foi de 7,62\%, a maior taxa alcançada no período, sendo que a taxa de crescimento do Brasil foi de apenas $1,14 \%$, o que mostra certo descolamento do desempenho econômico do estado em relação ao desempenho nacional. Segundo a Semac (2009), no período entre 2002 e 2003, o PIB do MS cresceu impulsionado principalmente pela produção agrícola. Já nos anos de 2004 e 2005, o desempenho oscilou de -1,28\% a 3,30\%, respectivamente. No período 2006 - 2008, a economia do estado voltou a acelerar o seu ritmo de crescimento, registrando um aumento na taxa real média do PIB de $5,79 \%$. No entanto, no ano de 2009 sofreu uma queda brusca na taxa de crescimento de $0,42 \%$.

O que explica em grande parte a superioridade da taxa de crescimento do estado é o desempenho da agropecuária (setor primário) e da indústria (setor secundário). Enquanto para o Brasil esses dois setores apresentaram um PIB decrescente, para o MS os mesmos cresceram a taxas positivas no período (IPEADATA, 2013). 


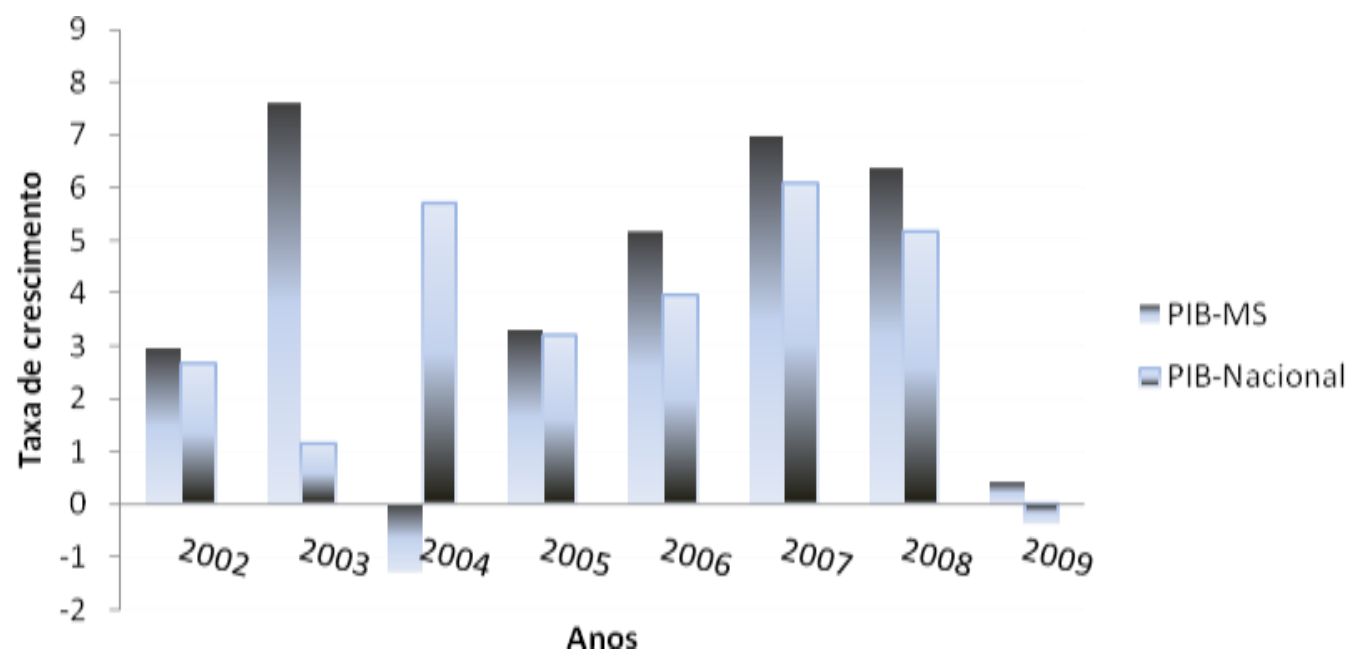

Figura 1 - Taxa de crescimento real do PIB do MS e do Brasil no período de 1996 a 2009

Fonte: Secretaria de Estado de Meio Ambiente, do Planejamento, da Ciência e Tecnologia (Semac) e Ipeadata.

No que se refere especificamente aos setores econômicos, cumpre observar que no MS o setor primário apresenta como destaque a cultura da soja, seguida pelas culturas de milho, arroz, trigo, mandioca, algodão, feijão, sorgo e cana-deaçúcar, presentes nas principais regiões agrícolas do estado. Por outro lado, a pecuária é constituída em sua maior parte pela criação de bovinos, aves e suínos.

O setor secundário, por sua vez, é o principal responsável pelo fornecimento de matéria-prima para a agroindústria. Mais especificamente, o setor industrial está direcionado ao beneficiamento de produtos advindos principalmente do setor agropecuário como grãos, algodão, carnes, leite, couro, cana, mandioca e minérios. $\mathrm{Na}$ agroindústria de transformação, destacam-se as cadeias de frigoríficos. Conforme Oliveira (2003), a agroindústria se instalou no Mato Grosso do Sul a partir da metade da década de 1980, resultante, em grande parte, do movimento de interiorização da indústria nacional e, também, em decorrência dos incentivos fiscais e da criação de linhas de financiamentos, principalmente para a instalação de unidades de beneficiamento de soja. Esse movimento provocou mudanças no seu perfil agrário-exportador.

Atualmente, o parque industrial do estado é constituído basicamente por quatro polos em fase de expansão, assim distribuídos (Semac, 2011):

i) Polo de Campo Grande - com segmentos industriais de frigoríficos, farinhas, farelos e óleos, curtumes, indústrias de madeira, mobiliária, vestuário etc., liderado pelos municípios de Campo Grande, Terenos e Sidrolândia.

ii) Polo de Dourados - com indústrias de farelo e óleos vegetais, frigoríficos (carne bovina, aves e suínos), indústria do álcool e do açúcar, erva-mate, têxtil, curtumes, beneficiamento de arroz, destacando os municípios de Dourados, Fátima do Sul, Itaporã e Rio Brilhante; 
iii) Polo de Três Lagoas - com indústria frigorífica, láctea, biscoitos, cerâmica, embalagens, álcool e açúcar, curtume, papel e celulose, indústrias de bebidas e de madeira etc., com maior expressão nos municípios de Três Lagoas, Paranaíba e Aparecida do Taboado; e

iv) Polo Industrial de Corumbá - com indústria extrativo-mineral, indústria de cimento, siderurgia, calcário, láctea, frigorífica e estaleiros, nos municípios de Corumbá e Ladário.

Ressalta-se, ainda, a perspectiva de desenvolvimento da indústria extrativista no estado dado as potencialidades minerais existentes, sobretudo, no que se refere às jazidas de ferro, calcário calcítico e dolomítico, manganês e mármore, entre outros. Ainda em fase inicial de exploração, este segmento industrial está localizado principalmente nos municípios de Corumbá e Ladário, onde se destacam a extração e beneficiamento de ferro, manganês e calcário; em Bodoquena, com a indústria de cimento; e, em Ribas do Rio Pardo, com a produção de ferro-gusa.

Ademais, recentemente ocorreu a consolidação da expansão sucroalcooleira. Essa expansão está associada a uma estratégia de atração das usinas sucroalcooleira, por meio principalmente de incentivos fiscais. Não obstante, devese destacar que o MS apresenta condições favoráveis à produção de cana-deaçúcar com disponibilidade de terras a preços competitivos, solos apropriados, localização estratégica e proximidade a grandes centros consumidores. Ou seja, o setor sucroalcooleiro está cada vez mais presente na economia do MS, em especial no que se refere à produção do etanol e do açúcar. Atualmente, existem 22 unidades industriais em operação localizadas em 18 municípios, sendo a maioria situada na região centro-sul, com exceção das unidades que estão localizadas nos municípios de Sonora, Aparecida do Taboado e Chapadão do Sul (regiões norte/nordeste).

O setor de serviços, por sua vez, tem apresentado taxas de crescimento positivas, em especial no que se refere aos subsetores de prestação de serviços de assistência para a agricultura, pecuária, agroindústria e, principalmente, de turismo. Ademais, destaca-se que grande parte da mão de obra ocupada neste setor está associada às atividades de comércio. Os investimentos em áreas essenciais oferecidas pelo poder público, como a educação, saúde e transporte, também têm aumentado significativamente.

\subsection{Dinâmica Setorial}

A seguir, apresentamos a taxa de crescimento real dos setores (Tabela 1), a participação desses na composição do produto (Tabela 2) e a composição do valor adicionado por subsetores (Tabela 3), as quais permitem fazer um mapeamento da composição e da evolução setorial recente no PIB do MS. 
Em relação às taxas de crescimento dos setores, é possível observar que o setor primário tem fortes oscilações ao longo do período, enquanto os demais setores apresentam taxas positivas de crescimento em todos os anos analisados. A taxa de crescimento média do setor primário é zero, o que explica a sua perda de participação na composição do produto ao longo do tempo. Ademais, observa-se uma perda significativa de importância da Agricultura nesse setor, tendo em vista que no inicio do período a mesma participava com $43 \%$ da sua composição, passando para 33,2\% em 2009.

Alguns fatores explicam essa perda de dinamismo da Agricultura como, por exemplo, os problemas enfrentados em 2004 pela insuficiência de chuvas no período de formação das culturas, principalmente nas regiões produtoras do sul do estado, o que provocou forte retração na produção. $O$ ano subsequente também foi marcado pelas dificuldades observadas na safra de grãos com a perda no volume colhido e com a redução nos preços. Em 2006, houve uma pequena melhora impulsionada principalmente pelo aumento do volume de produção das seguintes culturas: milho, $81,3 \%$; soja, $12,0 \%$; e cana-de-açúcar, $26,26 \%$. A recuperação continua em 2007 com o aumento das principais culturas de grãos, incluindo o algodão e a cultura da cana-de-açúcar. Todavia, o desempenho da economia do estado foi afetado pelos efeitos da crise financeira internacional que atingiu os grandes mercados consumidores em 2009 (nacionais e internacionais). A expectativa de redução na demanda por produtos primários gerou retração na produção de grãos, principalmente na soja, passando de 4.570 .771 toneladas para 4.046.223 toneladas, e no milho, com redução de 3.675 .526 toneladas para 2.181.429 toneladas em relação ao ano de 2008.

O desempenho da Pecuária também sofre oscilações no período. Inicialmente o setor perde participação, em grande parte devido aos impactos do aparecimento do foco da febre aftosa em municípios do sul do estado, que ocasionaram queda no valor da produção. Isso provocou perdas expressivas no setor com a eliminação de animais para atendimento das exigências sanitárias (efetivo bovino caiu de 24.504.098 de cabeças em 2005 para 23.726.290 em 2006) e com a impossibilidade de exportar carne e outros derivados da pecuária. Nos anos recentes o setor tem recuperado participação.

Tabela 1. Taxa de Crescimento real por setor de atividade, 2002-2009

\begin{tabular}{c|c|c|c}
\hline \multirow{2}{*}{ Anos } & \multicolumn{3}{|c}{ Setores de Atividades } \\
\cline { 2 - 4 } & Primário & Secundário & Terciário \\
\hline 2002 & $-5,15$ & 7,82 & 5,24 \\
\hline 2003 & 24,84 & 6,68 & 2,16 \\
\hline 2004 & $-20,97$ & 5,13 & 3,73 \\
\hline 2005 & $-1,92$ & 5,12 & 4,14 \\
\hline 2006 & 7,92 & 3,80 & 4,56 \\
\hline 2007 & 9,93 & 6,64 & 5,93 \\
\hline 2008 & 3,61 & 12,41 & 4,65 \\
\hline 2009 & $-13,47$ & 2,93 & 2,69 \\
\hline
\end{tabular}

Fonte: Elaboração própria com base nos dados do IBGE/Semac-MS. Nota: Ano-base: 1995. 
Os dados mostram que a taxa de crescimento do setor secundário é positiva ao longo do período e que o setor ganha participação na composição do PIB, ainda que em termos da composição do valor adicionado essa participação seja bastante inferior a da observada no Brasil. Dentre os seus subsetores, observa-se que o Extrativo-mineral e da Construção Civil perdem, enquanto os de Transformação e de Serviços industriais ganham participação relativa. Esse movimento faz com que aproximadamente $49 \%$ do setor secundário seja representado pelo setor de Transformação.

O bom desempenho do setor secundário tem sido observado nas diversas regiões do estado. Isso pode ser explicado pela política de incentivos fiscais e pelos recursos do Fundo Constitucional do Centro-Oeste e pelo apoio disponibilizado pelo Sistema Fiems (Federação das Indústrias de Mato Grosso do Sul), por meio do Sesi, Senai e IEL, com ações de educação básica e profissional, serviços de saúde, de lazer, técnicos e tecnológicos e encaminhamento para estágio. Ademais, a indústria de transformação, por exemplo, como as de carne, óleo de soja e ração animal, tem sido atraídas pela menor distância das fontes de matéria-prima.

O número de estabelecimentos industriais cresceu aproximadamente $16 \%$ entre 2002-2009. Usando os dados agregados disponibilizados pela SEMAC para o período 2002-2006 é possível observar que algumas atividades tiveram um crescimento significativo no número de estabelecimentos, dentre as quais se destacam: Borracha (300\%); Indústria Química (45\%) e Produção de Matérias Plásticas (37,5\%). A partir de 2007 os dados disponibilizados levam em consideração o ramo de atividade segundo a CNAE. Nesse período, as atividades que tiveram maior crescimento no número de estabelecimentos foram: Construção de obras de infraestrutura em geral (73,3\%); Produtos alimentícios - torrefação e moagem de café e Minerais não metálicos - fabricação de produtos cerâmicos (66,6\%); e, Confecção de roupas e artigos de vestuário e acessórios (56,7\%).

Uma forma alternativa de demonstrar a importância do setor secundário e da sua evolução na economia sul-matogrossense é analisar os dados da Relação Anual de Informações Sociais (RAIS). Segundo a mesma, a variação no número de empregos para os seguintes setores entre 2002 e 2009 foi de, aproximadamente: Extrativa Mineral (107\%); Indústria de Transformação (90\%); Construção Civil (76\%) e Servicos Industriais de Utilidade Pública (-0,02\%).

Por fim, cumpre ressaltar que a crise internacional teve efeitos negativos sobre o setor, tendo os impactos atingido principalmente as áreas ligadas à mineração, produção e exportação de ferro gusa e à indústria de alimentos, produção de carnes e derivados da soja destinados às exportações. 
Tabela 2. Evolução da participação dos setores de atividades na composição do $\mathrm{PIB} / \mathrm{MS}, 2002-2009$

\begin{tabular}{c|l|l|l|l|l|l}
\hline \multirow{2}{*}{ Anos } & \multicolumn{2}{|c|}{ Primário } & \multicolumn{2}{c|}{ Secundário } & \multicolumn{2}{c}{ Terciário } \\
\cline { 2 - 7 } & MS & Brasil & MS & Brasil & MS & Brasil \\
\hline 2002 & 22,31 & 6,62 & 16,71 & 27,05 & 60,99 & 66,33 \\
\hline 2003 & 24,72 & 7,39 & 15,70 & 27,85 & 59,58 & 64,77 \\
\hline 2004 & 20,93 & 6,91 & 19,21 & 30,11 & 59,86 & 62,97 \\
\hline 2005 & 15,45 & 5,71 & 17,24 & 29,27 & 67,31 & 65,02 \\
\hline 2006 & 14,53 & 5,48 & 18,46 & 28,75 & 67,01 & 65,76 \\
\hline 2007 & 15,80 & 5,56 & 16,68 & 27,81 & 67,52 & 66,63 \\
\hline 2008 & 16,60 & 5,91 & 17,64 & 27,90 & 65,76 & 66,19 \\
\hline 2009 & 15,53 & 5,63 & 18,48 & 26,83 & 65,99 & 67,54 \\
\hline
\end{tabular}

Fonte: Elaboração Própria com base nos dados do IBGE/Semac-MS

O setor terciário cresceu ao longo do período a uma taxa superior a $4 \%$. Ademais, a participação na composição do produto do estado é semelhante a do Brasil. Em termos relativos, os subsetores que ganharam participação foram: Comércio e Serviços de Reparação; Transportes; Administração Pública e Serviços Domésticos.

Segundo os dados da RAIS, o número de emprego no setor de Serviços cresceu aproximadamente $62 \%$ entre 2002-2009. Esse desempenho foi seguido de perto pelo setor de Comércio (60\%) e, em menor proporção, pelo setor de Administração Pública (24\%). Além disso, destaca-se que o setor terciário é responsável por mais de $70 \%$ dos empregos do estado.

O aumento da participação deste setor, tanto em nível federal como estadual, em parte está associado à crescente terceirização pelas empresas de parcela de suas atividades e de serviços. Sendo assim, o maior peso deste setor na formação da riqueza estadual reflete o comportamento dos setores econômicos, notadamente o da Indústria que vem ampliando o nível de terceirização de etapas de produção e dos serviços auxiliares, bem como a expansão e modernização do comércio (Semac, 2010).

\footnotetext{
${ }^{2}$ Dunning (1989) delimita seis tendências para explicar o crescimento da participação dos serviços no PIB, a saber: i) alta elasticidade-renda da demanda por serviços de consumo; ii) participação crescente dos serviços no consumo intermediário; iii) tendência das firmas em terceirizar atividades como contabilidade, auditoria, transporte e consultoria empresarial; iv) crescente importância do marketing, distribuição e manutenção pós-venda e assistência a fim de aumentar o valor adicionado da produção física, além do incentivo à produção de serviços intermediários (educação, telecomunicações), e finais (saúde), e de serviços diretamente relacionados com as funções de governo (cobrança de impostos, segurança social, dentre outros.); v) crescimento dos serviços financeiros, de seguros, de transporte, necessários para trazer maior eficiência à sociedade moderna; e, vi) habilidade do setor terciário em criar novos produtos e mercados.
} 
Tabela 3. Composição do valor adicionado do PIB bruto por setores, 2002-2009

\begin{tabular}{|c|c|c|c|c|c|c|c|c|}
\hline Setores de Atividade/Ano & 2002 & 2003 & 2004 & 2005 & 2006 & 2007 & 2008 & 2009 \\
\hline Primário & 22,31 & 24,72 & 20,93 & 15,45 & 14,53 & 15,8 & 16,6 & 15,53 \\
\hline Agricultura, Silvicultura e Extrativismo Vegetal & 9,73 & 13,61 & 8,52 & 3,67 & 3,71 & 6,05 & 5,63 & 5,17 \\
\hline Pecuária e Pesca & 12,58 & 11,11 & 12,4 & 11,78 & 10,82 & 9,75 & 10,97 & 10,36 \\
\hline Secundário & 16,71 & 15,7 & 19,21 & 17,24 & 18,46 & 16,68 & 17,64 & 18,48 \\
\hline Extrativo-Mineral & 0,47 & 0,41 & 0,24 & 0,45 & 0,6 & 0,36 & 1,17 & 0,44 \\
\hline Transformação & 7,79 & 8,72 & 9,96 & 8,52 & 9,12 & 8,16 & 8,36 & 9,02 \\
\hline Construção Civil & 6,57 & 4,29 & 5,94 & 5,21 & 5,66 & 5,89 & 5,93 & 6,2 \\
\hline Serviços Industriais de Utilidade Pública -SIUP & 1,88 & 2,27 & 3,07 & 3,06 & 3,07 & 2,28 & 2,18 & 2,82 \\
\hline Terciário & 60,99 & 59,58 & 59,86 & 67,31 & 67,01 & 67,52 & 65,76 & 65,99 \\
\hline Comércio e Serviços de Reparação & 12,08 & 14,53 & 13,58 & 15,16 & 13,57 & 15,4 & 16,35 & 15,85 \\
\hline Alojamento e Alimentação & 2 & 1,28 & 1,56 & 1,45 & 1,76 & 1,59 & 1,43 & 1,86 \\
\hline Transportes & 4,17 & 3,81 & 3,93 & 4,66 & 5,3 & 5,24 & 5,1 & 5,69 \\
\hline Informação & 2,86 & 2,84 & 2,9 & 3,25 & 2,89 & 2,59 & 2,51 & 2,49 \\
\hline Instituições Financeiras e Seguros & 5,54 & 4,36 & 4,08 & 5,32 & 5,31 & 5,27 & 4,61 & 4,57 \\
\hline Serviços Prestados às Famílias e às Associativas & 1,98 & 1,96 & 1,99 & 2,3 & 2,45 & 2,25 & 1,92 & 1,96 \\
\hline Serviços Prestados às Empresas & 2,09 & 2,67 & 2,64 & 2,9 & 3,02 & 2,4 & 2,47 & 2,22 \\
\hline Aluguel e Administração de Imobiliários & 10,01 & 9,15 & 8,86 & 9,96 & 9,03 & 9,09 & 8,17 & 8,14 \\
\hline Administração Pública - APU & 16,69 & 15,71 & 16,92 & 18,63 & 19,98 & 19,97 & 19,78 & 19,48 \\
\hline Saúde e Educação Mercantil & 2,06 & 1,81 & 1,93 & 1,94 & 1,91 & 1,82 & 1,68 & 1,71 \\
\hline Serviços Domésticos & 1,49 & 1,46 & 1,47 & 1,75 & 1,8 & 1,9 & 1,76 & 2,02 \\
\hline
\end{tabular}

Fonte: PAM/IBGE

\subsection{Dinâmica Regional}

O estado do MS está dividido em 11 microrregiões. A Tabela 4 mostra a dinâmica recente das economias regionais a partir da participação de cada microrregião (MRG) na composição do PIB estadual, no período de 2002 a 2009. As MRGs que tiveram maior participação foram Campo Grande, Dourados, Baixo Pantanal e Três Lagoas, registrando uma média de 34,4\%, 20,7\%, 7,85\% e $7,78 \%$, respectivamente. 
Tabela 4. Contribuição das microrregiões geográficas no PIB/MS, 1997-2009 (em $\%)$

\begin{tabular}{l|r|r|r|r|r|r|r|r}
\hline $\begin{array}{l}\text { Microrreg./ } \\
\text { Ano }\end{array}$ & 2002 & 2003 & 2004 & 2005 & 2006 & 2007 & 2008 & 2009 \\
\hline $\begin{array}{l}\text { Baixo } \\
\text { Pantanal }\end{array}$ & 6,43 & 6,77 & 6,82 & 7,75 & 8,95 & 8,18 & 9,51 & 8,42 \\
\hline Aquidauana & 2,72 & 2,56 & 2,77 & 2,94 & 2,99 & 2,88 & 2,70 & 2,69 \\
\hline Alto Taquari & 6,32 & 6,31 & 6,08 & 5,67 & 5,31 & 5,41 & 5,29 & 5,44 \\
\hline $\begin{array}{l}\text { Campo } \\
\text { Grande }\end{array}$ & 34,87 & 31,93 & 33,59 & 35,19 & 35,36 & 34,95 & 34,82 & 35,18 \\
\hline Cassilândia & 4,09 & 4,65 & 4,43 & 3,57 & 3,11 & 3,60 & 3,41 & 3,59 \\
\hline Paranaíba & 2,98 & 2,78 & 3,07 & 3,16 & 3,23 & 3,08 & 3,11 & 3,04 \\
\hline Três Lagoas & 7,10 & 7,20 & 7,99 & 8,14 & 8,17 & 7,54 & 7,62 & 8,52 \\
\hline Nova & & & & & & & & \\
Andradina & 3,44 & 3,64 & 4,27 & 4,18 & 4,34 & 3,91 & 3,58 & 3,55 \\
\hline Bodoquena & 3,15 & 3,03 & 3,12 & 3,14 & 3,19 & 3,05 & 3,10 & 3,08 \\
\hline Dourados & 22,29 & 24,27 & 20,57 & 19,63 & 18,81 & 20,79 & 20,24 & 19,78 \\
\hline guatemi & 6,61 & 6,86 & 7,29 & 6,63 & 6,53 & 6,60 & 6,52 & 6,72 \\
\hline Fonte
\end{tabular}

Fonte: Elaboração própria com base nos dados da Semac/MS

Com base nos dados para 2009 observa-se que a microrregião de Campo Grande é a principal em termos econômicos do Estado, tendo contribuído com $35,18 \%$ do PIB. Dentro dessa região, o município de Campo Grande é o maior polo econômico (centro industrial de serviços). A MRG de Dourados tem a segunda maior participação na composição do PIB (19,78\%), em que se destacam os polos dos municípios de Dourados (centro agroindustrial) e de Ponta Porã (centro de comércio e serviços). A terceira MRG de destaque é Três Lagoas, contribuindo com 8,52\% do PIB estadual (centro agroindustrial e centro de comércio e serviços). Nessa MRG apenas o município de Três Lagoas apresenta perfil voltado para os setores industriais e de serviços. Além disso, analisando a variação na participação das microrregiões na composição do PIB verificou-se que as microrregiões Baixo Pantanal e Três Lagoas foram as que registraram maior variação positiva (1,99 e 1,42\%, respectivamente), enquanto a microrregião de Dourados perdeu $2,5 \%$ de sua participação.

Em termos da variação por setores de atividades entre os períodos de 2002 a 2009 (Tabela 5), verificou-se que as microrregiões que tiveram maior redução na participação do setor primário no valor adicionado do produto foram: MRG Cassilândia (-15,31\%); MRG Três Lagoas (-12,67\%) e MRG Dourados (-10,9\%). Cumpre observar que a primeira dessas microrregiões é fronteira agrícola com elevado grau de mecanização. Não obstante, nos últimos anos a participação da agropecuária na composição do PIB reduziu-se em grande parte como reflexo das dificuldades enfrentadas pelo setor.

Em relação ao setor secundário, as microrregiões que mais aumentaram a sua participação na composição do PIB foram: MRG Três Lagoas (13,3\%); MRG Nova Andradina (5,9\%) e MRG Iguatemi (3,14\%). Destaca-se que na segunda microrregião referida as atividades industriais estão localizadas principalmente nos municípios de Bataguassu, Bayporã e Nova Andradina, enquanto que na terceira essa variação positiva está ligada, principalmente, ao desempenho do município de Naviraí. 
Por fim, as microrregiões onde o setor terciário teve maior aumento na sua participação na composição do valor adicionado do produto foram: MRG Cassilândia (15,6\%), MRG Dourados (10,5\%) e MRG Alto Taquari (7,93\%). Observa-se que esse aumento nas duas primeiras microrregiões é de magnitude muito próxima à perda de participação do setor primário. Ou seja, houve uma reorganização da estrutura produtiva dessas regiões.

Tabela 5. Evolução da participação dos setores de atividades na composição do PIB/MS- $2002-2009$

\begin{tabular}{l|l|l|l|l|l|l}
\hline \multirow{2}{*}{\begin{tabular}{l} 
Microrregiões \\
\cline { 2 - 7 }
\end{tabular}} & Agropec. & Indústria & $\begin{array}{l}\text { Com. } \\
\text { Serv. }\end{array}$ & Agropec. & Indústria & $\begin{array}{l}\text { Com. e } \\
\text { Serv }\end{array}$ \\
\hline MRG Baixo Pantanal & 18,93 & 10,55 & 70,52 & 14,58 & 11,39 & 74,02 \\
\hline MRG Aquidauana & 28,43 & 10,85 & 60,71 & 26,7 & 12,9 & 60,4 \\
\hline MRG Alto Taquari & 43,28 & 9,91 & 46,81 & 33,31 & 11,95 & 54,74 \\
\hline MRG Campo Grande & 5,71 & 19,86 & 74,44 & 4,23 & 18,63 & 77,14 \\
\hline MRG Cassilândia & 44,1 & 12,63 & 43,27 & 28,79 & 12,26 & 58,95 \\
\hline MRG Paranaíba & 32,96 & 13,48 & 53,56 & 26,91 & 16,19 & 56,9 \\
\hline MRG Três Lagoas & 32,67 & 21,83 & 45,5 & 20,00 & 35,19 & 44,8 \\
\hline MRG Nova & 26,25 & 22,97 & 50,78 & 18,6 & 28,9 & 52,5 \\
\hline Andradina & 32,41 & 11,57 & 56,02 & 28,5 & 14,22 & 57,28 \\
\hline MRG Bodoquena & 27,89 & 15,87 & 56,24 & 16,95 & 16,28 & 66,78 \\
\hline MRG Dourados & 30,87 & 15,9 & 53,22 & 24,17 & 19,04 & 56,79 \\
\hline MRG Iguatemi & 22,31 & 16,71 & 60,99 & 15,53 & 18,48 & 65,99 \\
\hline Média no estado
\end{tabular}

Fonte: Elaboração própria com base nos dados da Semac.

Nas demais microrregiões essa variação na composição do PIB foi menos acentuada. A MRG do Baixo Pantanal, por exemplo, embora seja influenciada pelo crescimento da pecuária bovina, da extração mineral e do comércio, foram os setores da indústria e dos serviços que ganharam participação $(0,8$ e 3,5\%, respectivamente). Nessa microrregião, o município de Corumbá concentra a maior parte do PIB e se apresenta como polo de comércio e de serviços, voltado principalmente para o turismo, além de ser um centro de pecuária extensiva de corte. A MRG Bodoquena apresentou comportamento semelhante no que se refere ao aumento da participação dos setores secundário $(2,65 \%)$ e terciário $(1,26 \%)$. Nesta região, como parte do setor terciário destacam-se os pólos turísticos de Bonito, Jardim e Nioaque. No setor primário, os municípios que se destacam são Caracol e Nioaque e na indústria, Bodoquena e Bela Vista.

Por fim, a MRG de Aquidauana foi a que apresentou menor taxa de variação na composição dos setores no valor adicionado. O setor que mais ganhou participação foi o setor secundário (2,05\%). Nesta MRG, destacam-se os municípios de Aquidauana e Miranda como os dois maiores polos agropecuários regionais. Já a microrregião de Paranaíba teve uma variação negativa acentuada no que se refere à participação do setor primário na composição do PIB (-6,05\%). Nessa MRG, o município de Paranaíba destaca-se como polo econômico, enquanto os municípios de Aparecida do Taboado e Paranaíba concentram a maior parte da indústria (agroindústria). 
Com base nessa análise, é possível identificar três tendências no que se refere à dinâmica econômica das microrregiões: em primeiro lugar, observamos que a participação na composição do PIB de cada microrregião teve pouca variação, o que significa que ao longo do período, a forma como o valor da produção está distribuído entre as regiões não se modificou significativamente; em segundo, é possível observar no que se refere à variação entre os setores de atividade que houve mudanças significativas, uma vez que, em geral, o setor primário perdeu participação em todas as regiões enquanto aumentou a participação do setor secundário e, principalmente, do setor terciário; e, por fim, que as maiores taxas de variação entre setores ocorreram naquelas regiões onde inicialmente o setor primário tinha maior participação (MRGs de Cassilândia, Alto taquari e Três Lagoas).

A análise despendida mostrou a redução da participação relativa do setor agrícola na composição do PIB do MS. Cabe ressaltar, entretanto, que o mesmo mantém grande relevância econômica no estado, sobretudo com as culturas da soja e da cana-de-açúcar, que têm aumentado sua produção consideravelmente nos últimos anos. A seguir, analisa-se a evolução e o desempenho das principais culturas agrícolas do estado, no intuito de mostrar a "força" desse setor para a economia estadual.

\section{Força do Campo: a evolução das principais culturas agrícolas}

Nesta seção se analisa o desempenho recente das principais culturas agrícolas no estado de Mato Grosso do Sul. No primeiro biênio, pode-se observar uma significativa expansão na produção de grãos (Tabela 6). A taxa de crescimento foi de $52,17 \%$ e a safra superou em 2,7 milhões de toneladas a do ano anterior, com ganho de produtividade de $18,4 \%$. O maior destaque foi a expansão da produção de soja $(25,2 \%)$. No entanto, para os dois anos seguintes essa trajetória de expansão não se verificou. Ou seja, para o biênio 2004-2005, a taxa de crescimento da produção foi negativa em aproximadamente $17 \%$. No biênio seguinte, ocorreu uma recuperação com taxas relativas altas: 22,25\% em 2007 e $5,31 \%$ em 2008, seguida de uma queda brusca de $-23,02 \%$ em 2009.

Tabela 6. Evolução das principais culturas agrícolas no MS, 2002-2009

\begin{tabular}{c|c|c|c|c|c|c|c|c}
\hline Anos & 2002 & 2003 & 2004 & 2005 & 2006 & 2007 & 2008 & 2009 \\
\hline $\begin{array}{c}\text { Produção } \\
\text { (t) }\end{array}$ & 5.210 .106 & 7.954 .121 & 6.541 .760 & 5.752 .317 & 7.031 .961 & 8.459 .260 & 8.908 .101 & 6.857 .368 \\
\hline $\begin{array}{c}\text { Área } \\
\begin{array}{c}\text { olhida } \\
\text { (ha) }\end{array}\end{array}$ & 1.870 .891 & 2.411 .460 & 2.795 .496 & 2.705 .410 & 2.774 .813 & 2.789 .864 & 2.918 .854 & 2.775 .069 \\
\hline $\begin{array}{c}\text { Produt. } \\
\text { (kg/ha) }\end{array}$ & 2.785 & 3.298 & 2.340 & 2.126 & 2.534 & 3.032 & 3.051 & 2.472 \\
\hline
\end{tabular}

Fonte: Elaboração própria a partir dos dados da PAM-IBGE. Nota: Inclui as culturas de soja, arroz, algodão, trigo, feijão e sorgo.

Juntamente com as culturas da soja e do milho, destaca-se no Brasil e no MS atualmente a expansão da cultura da cana-de-açúcar. Durante a crise do petróleo nos anos 1970, o governo brasileiro criou o Programa Nacional de Álcool (Proálcool) com o objetivo de ampliar a oferta de álcool, combustíveis e reduzir as 
importações de petróleo. A partir desse programa, essa cultura ganhou destaque na produção agrícola nacional, tendo, nas últimas décadas se intensificado.

A seguir apresentamos o desempenho das culturas de cana-de-açúcar, soja e milho no MS. A Tabela 7 apresenta os dados para o primeiro período da década. Como observado, nesse período a produção de cana-de-açúcar começa a se destacar, com uma taxa de crescimento ao longo do período de $26 \%$. A produção da soja segue a tendência e tem para o período uma taxa de crescimento de $19 \%$. O destaque negativo é a produção de milho que diminui em $41 \%$. Não obstante, essa queda na produção é precedida de um aumento considerável nos anos de 2003 e 2004.

O que chama atenção nesse período é a expansão da produção mesmo diante de uma série de dificuldades, sobretudo no final do período, como aquelas advindas dos fatores climáticos que provocaram estiagem, bem como a retração de preços nos produtos agrícolas, principalmente no que se refere à soja ${ }^{3}$.

Tabela 7.1 Evolução das culturas agrícolas no MS, 2001 a 2005

\begin{tabular}{c|c|c|c|c|c}
\hline Anos & 2001 & 2002 & 2003 & 2004 & 2005 \\
\hline Cana-de-açúcar & 7.556 .956 & 8.575 .190 & 9.030 .833 & 9.572 .305 & 9.513 .818 \\
\hline Soja (em grãos) & 3.115 .030 & 3.267 .084 & 4.090 .892 & 3.282 .705 & 3.718 .514 \\
\hline Milho (em grãos) & 2.185 .846 & 1.381 .604 & 3.071 .632 & 2.374 .015 & 1.291 .901 \\
\hline
\end{tabular}

Fonte: Elaboração própria a partir dos dados do PAM-IBGE.

No período seguinte observa-se um aumento significativo na produção das culturas em análise (Tabela 8). Ademais, é possível identificar que neste período ocorreu um "boom" na produção da cana-de-açúcar, que teve um aumento de $189 \%$ para o período. As outras culturas também tiveram um bom desempenho a produção da soja cresceu a uma taxa de $28 \%$ e a do milho, $61 \%$.

Tabela 8. 2Evolução das culturas agrícolas no MS, 2006 a 2010

\begin{tabular}{c|c|c|c|c|c}
\hline Anos & 2006 & 2007 & 2008 & 2009 & 2010 \\
\hline Cana-de-açúcar & 12.011 .538 & 15.839 .993 & 21.362 .034 & 25.228 .392 & 34.795 .664 \\
\hline Soja (em grãos) & 4.153 .542 & 4.846 .031 & 4.570 .771 & 4.046 .223 & 5.340 .462 \\
\hline Milho (em grãos) & 2.342 .619 & 2.972 .221 & 3.675 .526 & 2.181 .429 & 3.782 .946 \\
\hline
\end{tabular}

Fonte: Elaboração própria a partir dos dados do PAM-IBGE.

\footnotetext{
${ }^{3}$ Segundo Coronel et al. (2008), no ano 2004, o Brasil sofreu restrições por parte da China, que exigia a certificação do grão devido aos produtos geneticamente modificados e, posteriormente, devido à presença de grãos com ferrugem. Como resultado, os exportadores brasileiros, para não perderem os vários carregamentos, tiveram que se ajustar às exigências chinesas e ainda baixaram os preços.
} 
Tendo em vista o crescimento expressivo da produção de cana-de-açúcar e do setor sucroalcooleiro analisa-se com mais detalhes o desempenho desse setor no estado comparativamente ao Brasil (Tabela 9). Observa-se que em nível estadual a produção, a produtividade e a produção do açúcar e do etanol são superiores àquelas observadas em âmbito nacional, mostrando a importância crescente desse setor no estado. Ademais, ressalta-se que o Brasil é o maior produtor mundial de cana-de-açúcar, com aproximadamente 717 milhões de toneladas, considerando o ano de 2010. Nesse contexto, o estado de Mato Grosso do Sul ocupa $05^{\circ}$ lugar no ranking dos estados produtores, com aproximadamente 35 milhões de toneladas e produtividade de $87 \mathrm{~kg} / \mathrm{ha}$.

Tabela 9. 3Variação percentual do setor sucroalcooleiro no MS e Brasil, 2000-2010

\begin{tabular}{l|c|c}
\hline Discriminação & Mato Grosso do Sul & Brasil \\
\hline Produção de cana-de-açúcar & 496,08 & $120,0 \%$ \\
\hline Produtividade média da cana (kg/ha) & 49,15 & 16,45 \\
\hline Produção de etanol & 486,0 & 162,46 \\
\hline Produção de açúcar & 473,45 & 109,51 \\
\hline
\end{tabular}

Fonte: Elaboração própria a partir dos dados da PAM-IBGE

No que se refere à dinâmica regional, é possível observar que a produção de grãos e da própria cana-de-açúcar está distribuída de forma concentrada (Tabela 10). Analisando a dinâmica regional das principais culturas no Estado de 1980 a 2010, observa-se que a microrregião de Dourados, em 1980, era responsável por $65,63 \%$ do volume de soja produzida e pela produção de $49 \%$ do total de grãos. Esta microrregião se manteve ao longo do período responsável pela maior parte da produção estadual de grãos, mantendo, em 2010, um percentual de produção de $45,70 \%$ para a soja e de $58,3 \%$ para o milho.

Em termos da variação média, as microrregiões que ganharam participação na produção de grãos foram as MRG Cassilândia (11,7\%), MRG Alto Taquari $(7,86 \%)$ e da MRG Dourados (6,52\%). A microrregião que mais perdeu participação foi a MRG Campo Grande (-10,11\%), seguida da MRG Paranaíba ($4,99 \%$ ) e MRG Nova Andradina (-2,57\%). A microrregião que apresenta a menor participação no final do período analisado é MRG Paranaíba, registrando média de $0,07 \%$ para a produção das principais culturas. 
A dinâmica econômica recente do Estado de Mato Grosso do Sul: uma análise da composição...

Tabela 10. Produção agrícola das principais culturas segundo as Microrregiões, $1980-2010$

\begin{tabular}{l|c|c|c|c|c|c|c|c|c|c|c|c}
\hline & \multicolumn{5}{|c}{ Soja } & \multicolumn{4}{c|}{ Milho } & \multicolumn{4}{c}{ Outros (1) } \\
\hline Anos & 1980 & 1990 & 2000 & 2010 & 1980 & 1990 & 2000 & 2010 & 1980 & 1990 & 2000 & 2010 \\
\hline Bodoquena & 1,05 & 2,58 & 1,51 & 1,55 & 4,62 & 0,74 & 2,65 & 1,67 & 3,37 & 3,56 & 3,1 & 1,79 \\
\hline C. Grande & 19,88 & 4,71 & 8,43 & 8,75 & 12,72 & 17,6 & 4,60 & 11,6 & 25,50 & 9,02 & 5,21 & 7,41 \\
\hline Cassilândia & 4,12 & 17,1 & 15,69 & 9,44 & 4,50 & 16,4 & 25,14 & 10,1 & 2,90 & 0,65 & 29,03 & 27,1 \\
\hline Aquidauana & 0,62 & 0,21 & 0,01 & 0,01 & 6,05 & 1,87 & 0,16 & 0,08 & 4,94 & 2,95 & 6,58 & 4,32 \\
\hline Iguatemi & 2,37 & 2,44 & 1,87 & 8,3 & 18,37 & 9,95 & 6,52 & 10,3 & 7,10 & 16,21 & 4,05 & 2,52 \\
\hline $\begin{array}{l}\text { Três } \\
\text { Lagoas }\end{array}$ & 1,10 & 4,85 & 3,72 & 0,91 & 2,74 & 1,9 & 0,67 & 0,16 & 3,45 & 2,14 & 0,28 & 0,74 \\
\hline $\begin{array}{l}\text { Alto } \\
\text { Taquari }\end{array}$ & 7,66 & 20,2 & 20,11 & 11,8 & 2,23 & 6,58 & 12,48 & 10,9 & 9,92 & 3,74 & 6,88 & 20,7 \\
\hline Paranaíba & 1,09 & 0,41 & 0,01 & 0,04 & 8,76 & 1,73 & 1,50 & 0,14 & 5,34 & 0,89 & 0,18 & 0,03 \\
\hline B. Pantanal & 0,11 & 0,12 & 0,01 & 0 & 1,33 & 1,09 & 0,20 & 0,01 & 0,57 & 0,29 & 0,22 & 0,24 \\
\hline Dourados & 61,63 & 46,2 & 47,61 & 58,3 & 30,79 & 35,1 & 45,34 & 54,2 & 35,42 & 55,37 & 43,60 & 34,9 \\
\hline $\begin{array}{l}\text { Nova. } \\
\text { Andradina }\end{array}$ & 0,36 & 1,25 & 1,04 & 0,92 & 7,88 & 2,01 & 0,74 & 0,79 & 1,51 & 5,16 & 0,87 & 0,31 \\
\hline
\end{tabular}

Fonte: Elaboração própria a partir dos dados da PAM-IBGE. (1) Refere-se às culturas de arroz, algodão, trigo, feijão e sorgo

A distribuição da produção de cana-de-açúcar entre as microrregiões é apresentada na Tabela 11. Como observado, a produção no ano de 2008 estava concentrada em três microrregiões: MRG de Dourados, MRG de Iguatemi e MRG de Paranaíba. Já no ano de 2010, a produção de cana-de-açúcar concentrou-se em quatro microrregiões - Dourados, Iguatemi, Paranaíba e Alto Taquari - que responderam por $84,0 \%$ da produção do estado. Na microrregião de Paranaíba, verificou-se queda em relação a 2008, passando de 10,28\% para 6,52\%, enquanto a microrregião do Alto do Alto Taquari teve um crescimento significativo, passando de 5,11\% em 2008 para 6,34\% em 2010.

Tabela 11. Produção de cana-de-açúcar por microrregiões, 2008 e 2010

\begin{tabular}{l|c|c|c|c}
\hline Anos & \multicolumn{2}{|c|}{2008} & \multicolumn{2}{c}{2010} \\
\hline MRG & $\begin{array}{c}\text { Quant. } \\
\text { Produzida (t) }\end{array}$ & $\begin{array}{c}\text { Participação } \\
(\%)\end{array}$ & $\begin{array}{c}\text { Quant. Produzida (t) } \\
\text { MRG Dourados }\end{array}$ & $\begin{array}{c}\text { Participação } \\
(\%)\end{array}$ \\
\hline MRG Iguatemi & 4.237 .928 & 49,10 & 18.133 .630 & 52,11 \\
\hline MRG Paranaíba & 2.195 .400 & 19,84 & 6.616 .493 & 19,02 \\
\hline MRG Alto Taquari & 1.091 .430 & 5,11 & 2.268 .559 & 6,52 \\
\hline MRG Três Lagoas & 1.020 .435 & 4,78 & 2.077 .152 & 6,34 \\
\hline MRG Nova Andradina & 1.033 .889 & 4,84 & 1.970 .307 & 5,66 \\
\hline MRG Campo Grande & 1.210 .795 & 5,67 & 853.370 & 2,45 \\
\hline MRG Aquidauana & 73.745 & 0,35 & 622.627 & 1,79 \\
\hline MRG Bodoquena & 7.720 & 0,04 & 29.328 & 0,08 \\
\hline MRG Baixo Pantanal & 2.800 & 0,01 & 14.770 & 0,04 \\
\hline MRG Cassilândia & 0,00 & 0,00 & 2.800 & 0,01 \\
\hline TOTAL MS & 21.362 .034 & 100,00 & 34.795 .664 & 100,00 \\
\hline
\end{tabular}

Fonte: Elaboração própria com base nos dados do PAM/IBGE. 


\section{Considerações Finais}

Ressalta-se que, ainda que o estado do MS não seja fortemente industrializado, o que pode sugerir que as mudanças ocorridas com a reconfiguração produtiva aprofundada na década de 1990 no Brasil não tiveram impactos sobre a sua estrutura produtiva, que não só a lógica dessas mudanças passou a permear as atividades produtivas do MS, como também efetivamente propiciaram mudanças, sobretudo, ao reorganizar as técnicas de produção. Em outras palavras, a reestruturação produtiva inseriu na lógica produtiva sulmatogrossense a busca pela competitividade, em especial no setor agropecuário, que compete com o mercado de commodities internacional, bem como aprofundou o processo de mecanização da produção e a própria orientação da produção com o processo de seleção de novas culturas nesse setor, assim como intensificou o processo recente de industrialização e de desenvolvimento do setor de Serviços. .

Evidentemente, como a matriz produtiva do estado é diferente dos principais centros produtivo-econômicos do Brasil, as mudanças oriundas desse processo de reestruturação produtiva têm componentes específicos atrelados à produção e à organização da produção local. Nesse sentido, ainda que tenha ganhado participação na composição do PIB, o setor Industrial - identificado como o setor capaz de gerar movimentos propulsores de expansão e de encadeamento entre os polos desenvolvidos e as regiões menos dinâmicas - tem desenvolvimento precoce no estado. Ou seja, faltam investimentos e incentivos para a ampliação desse setor.

Ademais, observa-se que, apesar da "nova" dinâmica produtiva, permanecem no estado os problemas associados à forma desequilibrada e concentradora da produção. Ou seja, atualmente, quatro municípios são responsáveis por mais de $50 \%$ do PIB. Esses são os municípios de destaque dentro dos seus respectivos "polos de desenvolvimento". Não obstante, mesmo com a formação desses pólos, o que se observa é que historicamente não se tem conseguido estabelecer contrapesos aos efeitos espacialmente concentradores da atividade produtiva no estado.

Por fim, observa-se que, ainda que existam elementos que respaldam mudanças recentes na produção do estado, permanecem outros que marcam a sua formação histórico-econômica, como aqueles relacionados às políticas de desenvolvimento regional (marcha para o oeste, por exemplo) que determinam a forte orientação agrícola preponderante até os dias atuais. Ou seja, a região sulmatogrossense permanece inserida no cenário internacional como fornecedora de commodities.

\section{REFERÊNCIAS}

ABREU, S. O Mato Grosso do Sul no contexto das políticas de regionais de desenvolvimento. Dourados: UFMS, 2001.

CORONEL, D. A.; MACHADO, J. A. D; CARVALHO, F. M. A. de. Competitividade das exportações do complexo soja brasileiro. Revista Paranaense de Desenvolvimento, Curitiba, n.114, p.133-52, jan./jun. 2008. 
CORRÊA, V. B. Coronéis e bandidos em Mato Grosso: 1889-1943. 2.ed. rev. e atual. Campo Grande, MS: Ed. UFMS, 2006. 235p.

DUNNING, J. H. Multinational enterprise and the growth of services: Some conceptual and theoretical issues. The Services Industries Jornal, v.9, p. 5-39, 1989.

ESSELIN, P. M. História de Mato Grosso do Sul. In: MATO GROSSO DO SUL. Secretaria de Estado de Meio Ambiente, Cidade, Planejamento, Ciência e Tecnologia. Zoneamento Ecológico-Econômico do Mato Grosso do Sul: Contribuições Técnicas, Teóricas, Júrídicas e Metodológicas.V. I, SEMAC/MS, 2009.

FARIA, M. E. Agricultura Moderna, Cerrado e Meio Ambiente. In: DUARTE, L. M. G.; BRAGA, M. L. S. (Orgs). Tristes Cerrados: Sociedade e biodiversidade. Brasília: Paralelo 15, 1998.

GARCIA, D. S. C. Mato Grosso (1850-1889): uma província na fronteira do império. Dissertação de Mestrado, Universidade Estadual de Campinas - Unicamp. Instituto de Economia, Campinas, SP: 2001.

PAVÃO, E. da S. Formação, Estrutura e Dinâmica da Economia de Mato Grosso do Sul no Contexto das Transformações da Economia Brasileira, 2005. Dissertação (Mestrado em Economia Industrial). Universidade Federal de Santa Catarina, UFSC, Florianópolis, 2005.

QUEIROZ, P. R. C. O Desafio do Espaço Platino às Tendências de Integração do Antigo Sul de Mato Grosso do Sul ao Mercado Nacional Brasileiro: Um Hiato em Dois Tempos. Revista História em Reflexão; v. 3 n.6 UFGD/Dourados, jul./dez., 2009.

REIS NETO, J. F. dos. Plano de Desenvolvimento do Estado de Mato Grosso do Sul: Investigação dos Seus Atributos Relevantes. Porto Alegre: UFGRS/PPGA, dez. 2000.

Submetido em 08/02/2014

Aprovado em 05/12/2014

\section{Sobre os autores}

Fabricio Jose Missio

Doutor em Economia, Coordenador do Curso de Economia da Universidade Estadual de Mato Grosso do Sul.

Endereço: Br 463, Km 4. CEP 79900-000 - Ponta Pora - MS - Brasil.

E-mail: fabriciomissio@gmail.com

\section{Rosele Marques Vieira}

Doutora em Economia, Professora da Universidade Estadual de Mato Grosso do Sul. Endereço: BR 463-KM 4,5, Saida para Dourados. CEP 79900-000 - Ponta Porã - MS - Brasil. E-mail: rosele@uems.br 